\title{
FASCISMO EN ESPAÑA. POLÍTICA LOCAL Y CONTROL GUBERNATTVO EN LA CATALUÑA FRANQUISTA: ¿FUE EL PORCIOLISMO UNA FÓRMULA APERTURISTA?
}

\author{
por
}

MARTÍ MARÍN I CORBERA

Universidad Autónoma de Barcelona.

RESUMEN: Para contribuir al debate sobre el carácter de la dictadura franquista, el articulo examina una experiencia de larga duración (1957-1973) en el gobierno local de Barcelona, que sirvió además de modelo para el gobierno de las grandes ciudades durante el tardofranquismo. Si el régimen de Franco se configuró como fascista en su fundación durante la Guerra civily la más inmediata postguerra (1936-1942), es necesario evaluar su evolución posterior con la máxima atencion para establecer si con posterioridad se produjeron en él cambios lo suficientemente relevantes como para dejar de clasificarlo así. En este caso se aprecia como una experiencia que el régimen presentó a la opinión pública catalana como una modernización y una adapiación al signo de los tiempos, en un tono amable, ligeramente populista y, desde luego para nada fascista, resultó en términos politicos una acentuación del carácter jerárquico y centralizado del funcionamiento del poder local en Barcelona. Así el aperturismo porciolista resultó no sólamente perfectamente compatible con la Ley de $\mathrm{Ba}$ ses de Administración Local de 1945 - inspirada sin tapujos en la legislación local italiana de 1934-, sinó un reforzamiento de los aspectos más totalitarios de la misma.

PALABRAS CLAVE: España, dictadura de Franco, política municipal, Barcelona

ABSTRACT: To contribute to the debate over the nature of the Francoist dictatorship, the article looks into a long experience in local government (1957-1973) in Barcelona, which served as a model for the government of big cities in the last period of Franco's era. If Franco's regime was built as a fascist one during the Civil War and first postwar years (1936-1942), it's necessary to evaluate its evolution after that, to know if subsequent political changes was enough to modify that characterization. IVe can see in Barcelona's case bow political transformations in Franos's régime was only apparent. All reformist steps in local rule of big cities, like those of J.M.de Porcioles - Barcelona's mayor- in that period, were, in the end, increments in the mayor's control of the town council, and the central control of the mayor. So Porioles' liberatization was not only perfectly compatible with the Local Act of 1945, very similar to an Italian

Mippania, LVIIJ/2, núm. 199 (1998) 655-678 
one of 1934 under Mussolini, but reinforced tha Act's most totalitarian elements.

\section{KEY WORDS: Spain, Franco's regime, Local Government, Barcelona.}

Al régimen franquista puede considerársele, sin ningún género de dudas, como a un régimen fascista en la que podríamos llamar su fase formativa (1936-42). La mayoria de los estudios realizados sobre el mismo parecen así considerarlo pese a las diferencias de matiz. Las fórmulas utilizadas para estructurar el funcionamiento de su política interior, con mecanismos gubernativos de orden jerárquico y autoritario sin ningún tipo de juego representativo real ${ }^{1}$, y sus decisiones en materia económica, con política autárquica, sindicalismo vertical de inspiración básicamente propatronal, a pesar de sus contradicciones, y la férrea disciplina laboral implantada ${ }^{2}$, se movieron en esa dirección. Igualmente sus alineamientos internacionales desde 1936 hasta que la derrota del Eje se convirtió en una certeza insoslayable, no parecen dar mucho margen para la especulación sobre por qué nuevo orden internacional se estaba apostando y que tipo de papel se pensaba jugar en él ${ }^{3}$. Sus semejanzas con regímenes como el italiano, el portugués, el austríaco e incluso el alemán así lo confirman ${ }^{4}$.

1 El desarrollo de los mecanismos jerárquico-autoritarios dentro de las estructuras del régimen es uno de los aspectos de mi tesis doctoral, Politica i administració local durant el franquisme. Els ajuntaments de La Catalunya urbana entre 1938 i 1979, dirigida por Borja de Riquer, Universitat Autònoma de Barcelona 1993, en curso de publicación. Para un perfil de los gobiernos de Franco puede consultarse la caracterización que de los dos primeros realiza Javier TUSFI.L: Franco en la guerra civil. Una biografia politica., Tusquets, Barcelona 1992, asi como el reportaje periodístico del Equipo MUNDO: Los 90 ministros de Franco., Dopesa, Barcelona 1970. Sobre las limitaciones del juego representativo dentro del franquismo véase también Ángel GARROREN $\Lambda$ MORALIFS: Autoritarismo y control parlamentario en las Cortes de Franco. Universidad de Murcia, Murcia 1977.

2 Sobre economía, sindicalismo y condición obrera resultan de especial interés los trabajos de Jordi CATALAN: Los años cuarenta en la periferia europea: la economia española en perspectiva comparada. dentro de José Luis CASAS SÁNCHIEZ (coord.): La postguerra española y la Segunda Guerra Mundial, Diputación Provincial de Córdoba, Córdoba 1990, págs. 59-96 ; Manuel LuDEviD: Cuarenta años de sindicato vertical, Laia, Barcelona 1976; Carme MOLINILKO y Pere YSAS: «Patria, justicia y pany. Nivell de vida i condicions de treball a Catalunya, 1939-1951., La Magrana, Barcelona 1985 y Els industrials catalans durant el franquisme, Eumo, Vic 1991 y Ramón GARCÍA PINIIIRO: Las mineros asturianos bajo el franquismo (1937-1962)., Fundación Primero de Mayo, Madrid 1990.

3 Sobre la diplomacia franquista durante el periodo 1936-45 y su políica de equilibrios y su postrer «doble juego» tan corriente entre paises de segunda fila - como pudo comprobarse en los años 1943-45 en Europa del Este con los casos húngaro y rumano-- veánse Ángel VI. NAs: La Alemania nazi y el 18 de Julio., Alianza, Madrid 1974; Javier TUSELL y Genoveva QUEIPO DE LLANO: Franco y Mussolini. La politica española durante la segunda Guerra Mundial, Planeta, Barcelona 1985 y Paul PREsTON: Franco. «Caudillo de España», Grijalbo, Barcelona 1994.

4 Enzo COLloTTI: Cinque forme di fascismo europeo. Austria, Germania, Italia, Spagna, Portoga1ho dentro de Luciano CASALI (ed.), Per una definiz̧ione della dittatura franchista., Franco Angeli, Milán 1990, págs. 41-55.

Hitpania, LVIIJ/2, nu்m. 199 (1998) 655-678 
Llamar fascista al régimen de Franco después de 1945 puede resultar sin duda mucho más discutible, y se comprenden perfectamente las resistencias que se encuentran para seguir calificando así al régimen a medida que se adentra éste en los años cincuenta. Aunque no se trate, desde luego, de un tema tesuelto ni del que se dispongan aún de las investigaciones necesarias para el contraste de opiniones, como ya empieza a suceder con los años cuarenta. Pero resulta un claro anacronismo, inducido por el conocimiento que se tiene de su evolución posterior, dejar de llamárselo antes de 1945 ya sea por su menor "grado de totalitarismo" - cuando no existe ningún tipo de acuerdo sobre el contenido de una cualidad tan arbitrariamente definida como es esta- ${ }^{5}$, por su menor "grado de institucionalización» —cuando ello no implica otra cosa que un menor nivel de desarrollo formal pero no de desarrollo político práctico- o por el mero hecho de que el proyecto falangista "puro», identificado con Serrano Súñer y sus partidarios, no consiguiera la supremacía ${ }^{6}$. Dado, además, que existen indicios más que suficientes ya para no dar por agotada la nómina de los fascistas españoles con el simple recuento de los camisas viejas y sus eventuales compañeros de viaje dentro de FET-JONS 7 . Porque el contenido del término «fascista", lejos de poder aparecer como un objeto predeterminado, se va estableciendo progresivamente a medida que conocemos mejor el conjunto de regímenes dictatoriales, antiliberales, antidemocráticos y anticomunistas de la Europa de entreguerras. En éste sentido el término tiene un valor convencional como «demócrata», "comunista» o «liberab), no se trata de una mera descalificación, desde luego, aunque también tenga popularmente este uso. Utilizarlo significa ir más allá de las matizaciones que fabricaron para ser distinguidos entre sí, ya durante los años de pugnas internas, ya para su justificación a pasteriori los diversos grupos de colaboradores de tales regímenes, especialmente en España donde tanto tiempo e interés tuvieron para invertir en operaciones de maquillaje.

5 Véase la contundente afirmación que al respecto del carácter propagandístico del término realizó Renzo DE FELICE: Le interpretazioni del fascismo., Laterza, Bari 1976, pág. 91.

6 Son estos tres niveles los que concluye como básicos para impugnar el «fascismon del régimen la obra interpretativa más completa que se ha publicado hasta la fecha sobre el franquismo, Javier TUSELL: La dictadura de Franco, Alianza, Madrid 1988.

7 Véase a tal efecto el trabajo de Alfonso Borri, Cielo y dinero. el nacionalcatolicismo en España (1881-1975), Alianza, Madrid 1992, págs. 101-140. Ineludible también la consulta de las comunicaciones de Angela CENARRO, El control de la soczedad aragonesa, campo de batalla para la pugna entre la Iglesia y FET-JONS. y Antonio F. CANALES, Iglesia y totalitarismo, en E/ Régimen de Franco (1936-1975). Congreso Internacional. Madrid, majo 1993., vol.I, UNED, Madrid 1993, págs. 41-53 y 521-529, respectivamente. Resulta interesante contrastarlo con las reflexiones hechas para el caso italiano, por ejemplo, Giovanni MICCOLI, La Cbiesa e il fascismo, en VV.AA.: Fascismo e società italiana, Einaudi, Turin 1973, págs. 185-208; Franco BELCI, Storia naqionale e storia locale in alcuni studi su chiesa cattolica e fascismo, en Italia Contemporanea, núm.135, abril-junio de 1979, págs. 99-106 y Camillo BREzZI, I Patti lateranensi e il mondo cattolico, en Giovanni CHERUBINI et al, Storia della Società Italiana, vol.22, Teti, Milán 1983, pags. 195-231.

Hippania, LVIIJ/2, núm. 199 (1998) 655-678 
Ello plantea el error de creer en la existencia de un modelo "puro» de fascismo, ya sea en Italia o en Alemania, que deba de usarse necesariamente como unidad de medida - lo que no sucede cuando nos referimos ningún otro tipo de régimen-. Los términos "democrático», «socialista» o cualquier otro difícilmente se utilizan igual, con un modelo previo de referencia en algún lugar y tiempo concretos en la misma medida en que lo ha sido el régimen hitleriano; y podemos calificar con ellos a regímenes muy distintos sin generar polémica alguna por el hecho de que no se puedan identificar plenamente con EEUU o la desaparecida URSS. Es necesario, por lo tanto, apostat por la comparación entre regímenes para establecer paralelismos y no por la medición de los mismos, tal y como actua por ejemplo Enzo Collotti gracias a la ventaja que le confiere el haber realizado estudios monogràticos sobre diversos paises ${ }^{8}$, teniendo en cuenta que para la comparación es preciso primero el conocimiento de la realidad de los mismos mucho más que de las imágenes que estos regímenes proyectaron de sí o de las que proyectaron sus adversarios, como advirtió en su momento Alfonso Botti".

En el presente artículo se pretende desarrollar un aspecto del conjunto gubernativo del régimen de Franco, su régimen local, y en concreto su experimento aperturista más elaborado, para comprobar hasta que punto la evolución seguida por el mismo puede ofrecernos una imagen de incompatibilidad con la clasificación del mismo como fascista pata los años posteriores a la adaptación al nuevo concierto internacional de la segunda postguerra mundial. La referencia-marco es, como se desprende del título, la Barcelona de Porcioles (195773), con su Carta Municipal, su política presuntamente modernizadora y su petsonal dirigente renovador. Para ello será necesario previamente proceder a un anàlisis del régimen local construido por el franquismo y a su concreción en la Cata'uña urbana de las dos décadas previas al desarrollismo. El hilo conductor de la drgumentación será precisamente el de la adaptación que el franquismo realizó de sus estructuras gubernativas para sobrevivir e incluso para consolidarse y desarrollarse como un régimen estable en un medio, el area metropolitana de ${ }_{\mathrm{P}}$ arcelona, caracterizado por su superior dinamismo tanto económico como smi ial con respecto a la mayor parte del país en aquellos años. Es decir, como procedió el régimen para, lejos de desfallecer ante los cambios sociales que se producian a su alrededor, aumentar su solidez —al menos en primera instancia- sin necesidad de alterar sus mecanismos constitutivos originales. Huelga

8 Veánse los análisis comparativos de Enzo COLLOTTI,: Fascismo, fascismi, Sansoni, Florencia 1989 así como también sus trabajos Naquismo e società tedesca, 1933-1945., Loescher, Torino 1982; Fascismo e nazionalsocialismo, en N. TRANFAGLIA, Fascismo e capitalismo., Feltrinelli, Milán 1976; Considerazioni sull'«austrofascismon, en Studi Storici, múm.4, 1963 y Fascismo e Heimwebren: la lotta antisocialista nella crisi della prima reppublica austriaca. en Rivista di storia contemporanea., núm. 3, 1983, págs. 301-337.

${ }_{9}$ Alfonso BOT11, Los fantasmas de Clio. A propósito de franquisme y fosismo en la perspectiva de la bistoria comparada, en Anales de la Universidad de Alicante. Historia Contemporanea, num.8/9, Universidad de alicante 1993, págs. 21-34.

Hipania, LVIII/2, núm. 199 (1998) 655-678 
decir que el epílogo se halla en su fracaso para seguir con ese proceso "transformistay en los años setenta, cuando esos mismos mecanismos fueron puestos en cuestión por una oposición de masas, que aunque actuara de forma algo caótica en ocasiones y falta de organización bastante a menudo, resultó localmente muy efectiva.

\section{LA CONSTRUCCIÓN DEL. RÉGIMEN LOCAL EN LA ESPAÑA DE LA AUTARQUIA: IA EXPERIENCIA CATALANA}

A la hora de reconstruir el aparato gubernativo quebrado por el frustrado golpe de estado del 18 de julio, Franco y sus más cercanos colaboradores tuvieron un horizonte claro: ninguna institución del estado, fuera esta central o periférica podía suponer a corto, medio o largo plazo un posible contrapoder. Como Hitler o Mussolini, Franco debía de tener la capacidad incuestionable de decidir sobre su relevo o sucesión con independencia del carácter que tomase su gestión, que no podia ser fiscalizada. La cuestión del poder central por parte de otros aparatos del propio estado no iba a poner en peligro a Franco y a su régimen de la misma forma en que, se consideraba, bases de poder locales y/o regionales habían dado al traste con la monarquía de Alfonso XIII. No cabía la repetición de los considerados defectos del sistema liberal de la Restauración, que, con todas sus limitaciones, habían abierto una puerta a la cuestión del poder desde abajo. El Nuevo Estado iba a funcionar de una forma centralizada y jerarquizada a ultranza tal y como se había planteado en otros países en los que se había procedido a la implantación de un gobierno fascista ${ }^{10}$. Nadie iba a poder cuestionar el papel de dirigente absoluto de Franco y su gobierno.

Franco no era precisamente un experto en materia de doctrinas políticas, pero comprendía perfectamente el mecanismo esencial de funcionamiento de un régimen así concebido: una rígida disciplina impuesta de arriba a abajo tal y como se produce en el orden castrense. No en vano fue la experiencia combatentista la que modeló las fórmulas de organización del fascismo europeo al final de la I Guerra Mundial. La dirección del estado no iba a pasar, pues, por un juego de alternativas políticas, considerado quintaesencia de la debilidad, madre de todo desorden y antesala de la revolución. No más caciques con los que pactar equilibrios de poder local a cambio de fidelidad en el juego de los aparatos centrales del estado, como no fuera con la consideración previa de su absoluto sometimiento al gobierno, algo que marcaba un punto de inflexión con respecto a la España de Cánovas y Sagasta, cuando los notables locales tenían alternativas en sus vías de inserción en la política que se desarrollaba en torno a Madrid. Visto así el franquismo no fue, en absoluto, una segunda Restaura-

10 Para el caso italiano, sin duđa el más trabajado, ver, por ejemplo, Aiberto AQUARONE, L'organizzazione dello Stato totalitario, Einaudi, Turin 1965 y Ettore ROTELLI, Le trasformazioni del'ordinamento comunale e provinciale durante il regime fascista, en Sandro FONTANA (ed.), Il fascismo e te autonomie Locah, Il Mulino, Bolonia 1973. 
ción, salvo en el caso de que se acuda al paralelismo vago de resaltar que ambos regímenes se marcaron como objetivo preservar genéricamente el orden social. En el franquismo este orden se iba a garantizar a través de la sumisión incluso de estos personajes, que para participar del juego político iban a tener que demostrar su adbesión inquebrantable. De no producirse ésta el notable local debía limitarse a cuidar de sus intereses económicos sin entrar en la arena política, tal y como comprobaron dirigentes y militantes regionalistas catalanes, vascos y valencianos ${ }^{11}$. Su condición de poderes económicos no fue cuestionada en genetal, pero su papel político fue mayoritariamente rechazado para los más destacados y sometido a un intenso reciclaje en aquellos de los demás que apostaron por seguir en el juego ${ }^{12}$.

Respecto de los ayuntamientos, la política diseñada en el periodo previo a la aprobación de la Ley de Bases de Régimen Local (1945) recuperaba su función esencialmente gubernativa sometida al control de los gobiernos civiles, eliminando cualquier veleidad representativa. Sus miembros ya no iban a ser, como en la repetida cita del conde de Toreno ante las Cortes de Cádiz, unos agentes del gobierno elegidos de un modo particular, sino unos agentes del gobierno de libre designación. Esta caracterización no cambiaría con la implantación de las elecciones de concejales por tercios cada tres años. La apliación de la democracia orgánica en los consistotios no afectó a la discrecionalidad de los nombramientos de alcaldes, y nunca significó un verdadera fórmula electiva. El tercio corporativo siempre fue una designación directa fruto del pacto alcaldegobernador, el tercio sindical, compromisarios de por medio, del pacto tripartito alcalde-gobernador-delegado sindical local, y el familiar se resolvió en una mayoria de casos con un procedimiento cercano al de la lista única, garantizándose, al menos hasta 1966, la inexistencia de candidatos de la oposición anti-régimen cuando se llegaba a una convocatoria efectiva. Otra cosa serían los disidentes locales que cuestionaban al alcalde de turno sin salirse de los límites del estrecho consenso del régimen, éstos podían ser tolerados o desplazados según fuera la valoración que coyunturalmente realizara el gobernador civil. Un ejemplo de la práctica inexistencia de elecciones en la provincia de Barcelona hasta fechas tardías puede verse en el cuadro I, siendo significativo el cuadro II

11 Las experiencias de estas élites de poder regionales se analiza en A. F. CANALES, A. CE: NARRO, M. MARIN i R.VALLS, Els ajuntoments i el rnou ordres franquista, dossier publicado en L'Avenf, núm. 197, Barcelona, noviembre de 1995, págs. 18-41, así como en la tesis doctoral de Cándida CALVO VICENTE, Poder y consenso en Guipúzcoa durante el frantuismo, 1936-1951., Universidad de Salamanca 1994.

12 Véase, además, el caso de la Derecha Regional Valenciana en Rafael VALLS, La Derecha Regional Valenciana (1930-1936), Alfons el Magnànim, Valencia 1992, págs. 227-253 y E/ partit católic, Universitat de València, 1993. Para el regionalismo catalán en la postguerra és útil también la consulta de diversos momentos de la argumentación de Joan Maria THOMAS, Falange, Gwerra Civil, Franquisme. FET y de las JONS de Barcelona en els primers anys del franquisme., Publicacions de l'Abadia de Montserrat, Barcelona 1992. Finalmente resulta de interés para ese mismo caso la lectura de Borja de RIQULR, Un pais després d'una guerra (1939-1959), en Pierre VILAR (dir.), Història de Catalunya., vol.VII, Ed. 62, Barcelona 1989, especialmente págs. 59-63, 135-140 y 212-214.

Heipania, LVIII/2, núm. 199 (1998) 655-678 
de las dificultades puestas a toda penetración opositora al régimen como conjunto.

CUADRO I. ELECCIONES CELEBRADAS EN POBLACIONES DE MÁS DE 10.000 HABITANTES EN LA PROVINCIA DE BARCELONA, 1948-1973*

\begin{tabular}{||c|c|c|c|c|c|c|c|c|c|}
\hline Año & 1948 & 1951 & 1954 & 1957 & 1960 & 1963 & 1966 & 1970 & 1973 \\
\hline Núm. de elecciones & 13 & 7 & 1 & 2 & 1 & 4 & 9 & 20 & 24 \\
\hline Núm. de poblaciones & 14 & 17 & 17 & 19 & 24 & 24 & 32 & 38 & 38 \\
\hline
\end{tabular}

* Barcelona se ha excluido del computo de 1957 por tratarse de un año en el que su ayuntamiento no fue afectado por ningún tipo de renovación de cargos, mexced a la motatoria que en su día obtuvo Porcioles del Ministro de la Gobernación.

Elabozación propia a partir del fondo documental del Gobierno Civil de Barcelona.

\section{Cuadro $\boldsymbol{M}$. FIUIACIÓN POLIÍTICA DE LOS CONCEJALES ELEGIDOS EN CADA CONVOCATORIA EN LAS POBLACIONES URBANAS DE LA PROVINCIA DE BARCELONA, 1951-1973}

\begin{tabular}{|l|r|r|r|r|r|r|r|r||}
\hline & 1951 & 1954 & 1957 & 1960 & 1963 & 1966 & 1970 & 1973 \\
\hline FET-JONS & 74 & 141 & 78 & 117 & 82 & 85 & 36 & 52 \\
\hline ADICTOS & 18 & 14 & 39 & 50 & 74 & 70 & 90 & 120 \\
\hline INDIFERENTES & - & - & 1 & - & 3 & 7 & 7 & 9 \\
\hline DISIDENTES & - & - & - & - & - & 5 & 2 & 6 \\
\hline DESCONOCIDA & 18 & - & - & - & - & - & - & - \\
\hline TOTAL & 110 & 155 & 118 & 167 & 159 & 167 & 135 & 187 \\
\hline
\end{tabular}

Ibid. Las veinte poblaciones que se han utilizado comprenden el cinturón industrial de Barcelona y las cabeceras de partido judicial de toda la provincia: Arenys de Mar, Badalona, Barcelona, Berga, Cornellà, Granollers, Hospitalet de Llobregat, Igualada, Manresa, Mataró, Sabadell, Sant Adrià del Besòs, Sant Bơ de Llobregat, Sant Feliu de Llobregat, Sant Sadurni d'Anoia, Santa Coloma de Gramanet, Terrassa, Vic, Vilafranca del Penedès y Vilanova i la Geltrú.

Junto al control político de las corporaciones municipales, las depuraciones de funcionarios y el reemplazo de los considerados desafectos por ex-combatientes, ex-cautivos y todo género de personas vinculadas directa o indirectamente al esfuerzo de guerra dentro del bando Nacional, generaron un elemento importante de fidelidad a la maquinaria gubernativa. Una primera estimación de destituciones i otro tipo de sanciones puede apreciarse en el Cuadro III. Y, no obstante, esta maquinaria político-administrativa depurada fue, aun, refor- 
mada para extremar el control centralizado de la misma a través de unos gobiernos civiles, erigidos en el centro aglutinador de toda la gestión de la administración periférica del estado, con una casi ilimitada capacidad de inspección, fiscalización e incluso usurpación de competencias. $Y$ finalmente, la ya tradicionalmente débil hacienda local fue drásticamente golpeada en sus ingresos, a través de la supresión no compensada de diversos tributos locales, en especial el llamado Repartimiento General de Utilidades, y de la limitación de sus posibilidades de endeudamiento ${ }^{13}$. Tanto fue así que durante los años cincuenta se sucedieron los decretos reformadores de la fiscalidad local para evitar lo que se estaba conviertiendo en quiebra técnica de unos municipios que, pese a todo, tenían una mínima actividad urbanística - la parte del león de todo presupuesto local- . No deja de resultar significativo que se estuvieran repitiendo en la hacienda local española los mismos problemas que veinte años atrás habían surcado la hacienda local en la Italia fascista ${ }^{14}$

Desde luego que los paralelismos con el régimen local italiano del ventennio no se agotan con la mención a unas mismas debilidades fiscales, hijas en ambos casos del doble proceso de recorte de la capacidad impositiva municipal y aumento de los gastos de obligado cumplimiento, que le eran traspasados por la hacienda estatal como una forma encubierta de deshacerse de sus propias deudas. También en Italia se suprimieron todas las instancias electivas en la formación de los consistorios, si bién la complejidad del proceso de afirmación de la dictadura de Mussolini aconsejó hacerlo de un modo progresivo. Entre 1923 y 1925 se abusó de la legislación liberal en materia de destitución de ayuntamientos, sustituyendo un número escandalosamente elevado de ellos - tanto de mayoría socialista como poppolari- por comisarios regios o prefecticios ${ }^{15}$. En 1925 se creó la figura del podesta, alcalde de nombramiento gubernativo por un periodo de tiempo indefinido, para normalizar esta situación. El podesta debía asumir las funciones de toda la corporación cual si de un comisario gubernativo provisional se tratase, pero amparado ahora por una ley que anulaba todo proceso electoral para los comuni de menos de 5000 habitantes ( 7.337 sobre 9.148 en la mencionada fecha). En 1927 el resto de municipios sufrirían igual proceso, atendiendo al éxito conseguido en los municipios rurales. Desparecian de un plumazo el sindaco, alcalde elegido por la corporación desde 1888, y la propia corporación - giunta municipale $\mathrm{i}$ consiglio comunale--, elegida por sufragio

13 El perfil de la administración local de la postguerra y su análisis a partir de la experiencia catalana puede seguirse, además de en mi tesis doctoral citada, a través de mis artículos Franquismo y poder local. La puesta en marcha de la democracia organica en la Cataluña urbana, 1945-1957, en E/ Régimen de Franco (1936-1975). Congreso Internacional. Madrid, mayo 1993, cit., págs. 569-579 y Franquisme $i$ poder local. Construccio $i$ consolidacio dels ajuntaments feixistes a Catalunya, 1938-1949. en Recerques. Història, Economia, Cullura, núm. 31, Barcelona 1995, págs. 37-52.

14 Vid. Marti MARÍN i CORBERA: Les finances locals en el primer franquisme, 1939-1955, en III Congrés Internacional d'Història Local de Catalunya. Funcionament de les finances locals al llarg de la bistòria. Actes, L'Avenç, Barcelona, 1996, págs. 351-359.

15 Vid. Luigi PONZIANI, Fascismo e Merzogiono: la fine delle amministrazioni comunali. en Passato e presente, núm. 30, sept-dic.1993, págs, 53-78.

Hipaniu, LVIII/2́, núm. 199 (1998) 655-678 
universal masculino desde 1912. Para atender a las necesidades de gestión de los grandes municipios se puso en marcha en 1926 la creación de un órgano consultivo de nombramiento corporativo, la consulta municipale, obligatorio solamente para los mayores de 20.000 habitantes y los menores que fueran sedes de la administración gubernativa -capoluoghi-.. Igualmente tuvo que procederse con lentitud en la depuración del personal administrativo, prolongándose ésta durante toda la década de los veinte y sin llegar nunca a la profundidad del sistemático tamizado de todas y cada una de las plantillas de funcionarios locales miembro a miembro. La guerra evitó al franquismo el trabajo de dar tantos rodeos y le permitió seguir el camino más recto para la creación de juntas municipales y cuerpos de funcionarios que no contuvieran en sí ni tan siquiera la sombra de la disidencia.

\section{CUADRO III. DATOS SOBRE IA DEPURACIÓN DE FUNCIONARIOS} EN CATALUNYA

\begin{tabular}{|l|c|c|c|c|}
\hline \multicolumn{1}{|c|}{ Institución } & Destituidos & $\begin{array}{c}\text { Otras } \\
\text { sanciones }\end{array}$ & $\begin{array}{c}\text { Admitidos } \\
\text { sin sanción }\end{array}$ & Total \\
\hline Ayuntamiento de Barcelona & $25 \%$ & $44,5 \%$ & $26,7 \%$ & $96,2 \%$ \\
\hline Ayuntamiento de Girona & $7 \%$ & $9,3 \%$ & $83,7 \%$ & $100 \%$ \\
\hline Aynuntamiento de Hospitalet & $41 \%$ & $10,6 \%$ & $48,4 \%$ & $100 \%$ \\
\hline Ayuntamiento de Lleida & $56,7 \%$ & $8,6 \%$ & $34,7 \%$ & $100 \%$ \\
\hline Ayuntamiento de Sabadell & $18,4 \%$ & $5,1 \%$ & $76,5 \%$ & $100 \%$ \\
\hline Ayuntamiento de Tarragona & $21,3 \%$ & $42,2 \%$ & $36,5 \%$ & $100 \%$ \\
\hline Diputación de Barcelona & $6,5 \%$ & $7,9 \%$ & $85,6 \%$ & $100 \%$ \\
\hline Diputación de Lleida* & $25,7 \%$ & $11,5 \%$ & $62,8 \%$ & $100 \%$ \\
\hline Generalitat de Catalunya** & $94,7 \%$ & - & $5,3 \%$ & $100 \%$ \\
\hline
\end{tabular}

* El calculo se ha efectuado en este caso sobre los expedientes hallados, y no sobre la plantilla total existente como en el resto, sin contemplar los casos de abandono voluntario del cargo - supuesto aplicado a los funcionarios que no solicitaron el reingreso en 1938 cuando fue ocupada la ciudad-.

** La Generalitat fue disuelta y todos sus funcionarios (15.860) destituidos -incluidos aquellos adscritos a servicios provinciales- Se exceptuaron 753 casos, considerados funcionarios de la Diputación Provincial de Barcelona, incluidos en su depuración correspondiente.

Fuentes: Mercè BARAllat, La repressió a la posiguerra civil a Lleida (1938-1945), Abadía de Montserrat, 1991. Martí Marin i Corbera, Govern municipal i actituds politiques en el Sabadell del franquisme, en J. M. ${ }^{2}$ BENAUL, J. CALVET i E. DEU (ed.), Indústria i ciutat. Sabadell, 1800-1980, Abadía de Montserrat, 1994. Carme Molinero i Pere Ysàs, La Diputació de la postguerra: 19391949, en B. de RIQUER (dir.), Història de la Diputació de Barcelona., vol. 3, Diputació de Barcelona, 1988. Carles SANTACANA: Victoriosos y derrotats. El franquisme a l'Hospitalet, 1939-1951, Abadia de Montserrat, 1994. 
Para dirigir estos ayuntamientos en la Cataluña ocupada, los militares consideraron útil recurrir a los antiguos miembros de los consistorios de la Dictadura de Primo de Rivera, cuando se encontraton localmente disponibles, completando las gestoras provisionales con fieles partidatios del régimen provenientes de grupos católicos organizados, corporaciones patronales, asociaciones de propietarios, etc. Fue preciso llegar a 1941 para encontrar unas gestoras municipales más o menos consolidadas con un personal político unido por algún tipo de norte común, más allá de la ocasional colaboración con el ejército de ocupación a cargo de los que lo consideraron realmente como liberador. Esta cohesión fue conseguida a través de la adscripción común al nuevo partido único FET y de las JONS del conjunto heterogéneo de personas que había contribuido al triunfo en la guerra: ex-combatientes, ex-cautivos, contribuyentes y organizadores del Socorro Blanco y todos aquellos que cumplieron las condiciones exigidas por el régimen para conceder la categoría de militante. Así, tras de casi dos años de conflictividad política local, de la que participaton muy pocos y que siempre se desartolló de espaldas a la opinión pública, los vencedores en la pugna por controlar las Falanges locales accedieron a controlar las gestoras provisionales en toda la Cataluña urbana. Durante los años cuarenta no sería de otro modo. Las sucesivas y discrecionales renovaciones de las gestoras municipales se llevaron a cabo teniendo en cuenta este baremo de selección: la militancia en FET-JONS. Ello llevaría, no obstante, en una Cataluña de escasa presencia falangista y débil e irregular presencia carlista de preguetra agravada por el fracaso relativo de la unificación de 1937, a que accedietan a alcaldes de centros industriales y capitales de partido judicial individuos que podían haber pertenecido en el pasado a cualquiera de los partidos de derechas de la II República, incluidos el Partido Republicano Radical (p.e. Hospitalet, 1939-52 y Sant Boi de Llobregat 1939-40 y 1945-51) y la Lliga Regionalista (Badalona, 194045; Cornellà, 1945-51; Sant Boi de Llobregat, 1940-45; Sant Feliu de Llobregat, 1941 y 1945-47 y Sant Sadurní d'Anoia, 1939-42). Todos ellos se debian ahora al nuevo partido único en el que militaban, y fundamentalmente a la fidelidad al órden jerárquico gubernativo. Por ello dejaron de actuar como representantes de los grupos políticos a los que pertenecieron antes de $1936^{16}$. Su militancia nueva en FETJONS fue una forma de medir en primera instancia a quién se podía considerar como fiel al régimen y a su Caudillo.El partido adquirió así una función de filtro, de selección de personal. Cuando el nuevo falangista entraba en el juego del aparato del estado, la fidelidad a éste pesaba tmucho más que cualquier fidelidad partidista. La revolución pendiente dejaba de tener interés y no por ello dejaban de ser fascistas, dado que los falangistas auténticos no disponían de la patente ${ }^{17}$.

16 Ver Joan M. THOMÀs, Falange, Guerra Citril, Franquisme.

17 Ver Sheelag ELLWOOD, Prietas las filas. Historia de Falange Española, 1933-1983, Crítica, Barcelona 1984 y Martin BLINKHORN, Carlismo y contrarrevalución en España, 1931-1939, Crítica, Barcelona 1975. Titulos muchos más prudentes que el utilizado para caracterizar a la Falange por parte de Stanley G. PAYNE, Falange. Historia del fascismo expañol, Ruedo Ibérico, Paris 1965, donde se toma una parte por el todo.

Hispania, LVIII/2, núm 199 (1998) 655-678 
Las elecciones aportaron muy pocas novedades, salvo tal vez la presencia obligada de unos cuantos obreros falangistas de la rama sindical - casi siempre encargados y contramaestres de fábrica - en cada consistorio. Ni siquiera los concejales corporativos eran realmente de un origen distinto en los años cincuenta. Al fin y al cabo la presencia de militantes de FET-JONS en cualquier junta económica, social, cultural o prófesional de caràcter local era una realidad extendida. Así pues, cuando en 1957 el ayuntamiento barcelonés se aprestó a iniciar una nueva etapa con un nuevo alcalde, se correspondía perfectamente con esta imagen de consistorio fiel como un solo bombre a la estructura gubernativa pese a la pluralidad de orígenes de sus ediles, con un conjunto de funcionatios hechos fieles a través del tamiz de las depuraciones y unas finanzas tan estrechas que abocaban a una gestión del día a día con realizaciones paupérrimas en todos los capítulos. En el alba del desarrollismo el ayuntamiento de Barcelona, y con él todos los de la Cataluña urbana en general, seguían correspondiéndose con los que se construyeron dutante el periodo autárquico: unos instrumentos de control político de la vida local, sumisos a la jerarquía y absolutamente infradotados para afrontar cualquier obra de envergadura a beneficio de nadie. No és de extrañar que salvo por razones de notoriedad y piestigio local pocos de los ciudadanos considerados notables se sintieran atraidos por la gestión municipal, pasada una primera década en la que los ayuntamientos habían podido ser útiles para enriquecerse con el negocio de los abastos, fundamentalmente de forma ilegal. Nada en la actividad municipal cotidiana podía atraer a porciones significativas, cuantitativa o cualitativamente, del tejido social urbano a interesarse por el gobierno local. Las posibilidades de ganacias económicas se hallaban, desde luego, en otros lugares, e incluso era discutible que un ayruntamiento pudiera ser un trampolín adecuado para la promoción socio-política a mediados de los años cincuenta.

\section{BARCELONA EN LOS AÑoS CINCUENTA: EL AYUNTAMIENTO FRENTE A SUS CIUDADANOS}

Que el ayuntamiento de Barcelona era absolutamente impopular entre sus habitantes al abritse la década de los años cincuenta era un secreto a voces que estalló irremediablemente, entre las manos de quienes creían mantenetlo oculto, con la huelga de tranvías de 1951. Los hechos y sus valoraciones sociales y políticas más generales son suficientemente conocidos como para no tener que insistir aquí en ellos ${ }^{18}$. Con todo, hay que decir que aquella huelga resultó el detonante para la apertura de un nuevo periodo en la política provincial barcelonesa y, muy especialmente, en su capital. Los ceses del gobernador civil

18 Félix FANÉs, La vaga de tramvies del 1951., Laia, Barcelona 1977; Gemma RAMOS RAMOS Tranvías y conflictividad social en Barcelona (marzo de 1951): actitudes políticas y sociales de una huelga mítica, a Historia Contemporánea., núm. 5, Universidad del Pais Vasco 1991, págs. 203-217 y B. DE RIQUER, Un pair després d'una guerra, págs. 201-206. 
Eduardo Baeza Alegría y del alcalde de la Ciudad Condal, Josep Maria d'Albert i Despujol, barón de Terrades, fueton mucho más que un castigo a ambos por no haber podido evitar que la situación política ciudadana degenerara en el colapso temporal de la autoridad gubernativa. Su reemplazo vino a significar un punto de inflexión en el equilibrio de lo que hasta entonces había sido la política gubernativa en la ciudad y, por extensión, en todo el conjunto provincial. Su inspirador fue el gobernador civil de más largo mandato en la provincia (1951-1960), hasta que el no hace mucho Director General de la Guardia Civil, Ferran Cardenal, le superó (1983-1994). Se trató de Felipe Acedo Colunga, magistrado militar y fiscal en la revolución asturiana de 1934 y en el proceso a Julián Besteiro en 1939.

El boicot contra la subida de las tarifas de los tranvías había puesto al des-. cubierto toda una compleja serie de enfrentamientos entre sectores de FETJONS de la jefatura provincial barcelonesa y el gobernador civil, así como. también la estrechez de los centros de reclutamiento del personal político municipal en toda la provincia. La trama gobernador civil-alcalde-subjefe provincial del Movimiento había construido en el caso de Barcelona un equipo de gobierno al uso de la ortodoxia del régimen, con viejos monàrquicos de la oxidada nobleza local, antiguos colaboradores de la Dictadura de Primo de Rivera, algun regionalista de tercera fila convenientemente reconvertido y miembros de la Vieja Guardia y de la Delegación Provincial de Ex-Combatientes. Todos ellos de gris personalidad y nulo predicamento entre la burguesía local, salvo tal vez Epifanio de Fortuny, barón de Esponellà, destacado propietario agrícola de los llamados isidres - la patronal agraria catalana, Instituto Agrícola Catalán de San Isidro (IACSI) - , regionalista en su momento, cedista cuando fue conveniente y ahora falangista sospechoso, segun los que se autodefinian como auténticos. No era de extrañar, Baeza Alegría había heredado un gobierno civil ciertamente agitado y traspasado por las dificultades derivadas de las pugnas entre las diversas y estrechas camarillas falangistas, aún no recuperadas del mal trago que les supuso aceptar como dirigente durante dos años (1945-47) a Bartolomé Barba Hernández - militar de la UME y poco dado al exhibicionismo de camisa azulen sustitución del que fue considerado gobernador falangista por excelencia, Antonio F.de Correa Véglison (1940-45). Baeza Alegría asumió, un poco por azar ${ }^{19}$,

12 Eduardo Baeza Alegría, médico zaragozano afiliado a FET-JONS durante la Guerra Civil, presidente de la diputación de Zaragoza (1942-43) y gobernador civil de la misma (194347), organizó un brillante recibimiento a Franco durante una visita suya a la capital aragonesa. Parece que el Catdillo quedó gratamente impresionado y propuso su nombre cuando se produjo el fulminante cese de Barba Hernández. Para este perfil biográfico y el de otros gobernadores civiles en Cataluña ver Jaume FABRE / Josep Maria HUERTAS, Els governadors civils de Barcelona, en Jaume FABRE, Josep Mana HUERTAS i Antoni RJBAS, Vint anys de resistència catalana (1939-1959), La Magrana, Barcelona 1978, págs. 11-28; Josep CLARA, Els governadors civils del franquisme a Catalunya Notes sociologiques, en VV.AA.: L'êpoca franquista. Estudis sobre les comarques gironines, Cercle d'Estudis Històrics i Socials, Girona 1989, págs. 33-54 y Manuel RISQUES / Daniel CRLACH, El Gowern Civil de Barcelona. Una aproximacio bistorica, 1812-1978, 2 vols., inédito.

Hippania, LVIII/2, núm. 199 (1998) 655-678 
un gobierno civil vacante por el fulminante cese de su antecesor ante los incidentes catalanistas acontecidos en los actos de entronización de la Virgen de Montserrat en el emblemático monasterio benedictino, ante la presencia de diversas personalidades del régimen. Baeza Alegría ni consiguió reeditar el control de Correa Véglison sobre el aparato del partido ni acertó con la elección de su segundo de abordo, José Fernández Ramírez. Era este todo un veterano de la ultraderecha barcelonesa -UP, albiñanista y FE-JONS sucesivamentemuy aficionado a los juegos conspirativos. Habiendo sido expulsado de la $\mathrm{Fa}$ lange catalana en 1936, para reingresar tras el del 18 de Julio. Fernández Ramírez con su reducido grupo de amigos mantenía enfrentamientos casi seculares con otros no menos estrechos grupos falangistas barceloneses contribuyendo a comprimir drásticamente las posibilidades de elección de candidatos para concejal. Baeza Alegtía acabó por destituirle, lo que les situó en franco enfrentamiento, culminado cuando durante la huelga unos pasquines atribuidos a estos círculos falangistas acusaron al gobernador de ser el amante de la vedette del Teatro Cómico, la también aragonesa Carmen de Lirio ${ }^{20}$. Fernández Ramirez, que era a la sazón vicepresidente de la Diputación, acabaría por ser encarcelado durante la huelga. El alcalde d'Albert i Despujol, alfonsino de la línea de Derecha de Cataluña/Renovación Española (DC/RE) durante la República i presidente de la histórica factoría de La España Industrial, personalidad políticamente gris de un monarquismo ya trasnochado desde décadas atrás, tampoco ofrecía un abanico de contactos y posibilidades precisamente amplio para el reclutamiento de colaboradores en las labores municipales. Además los procesos electorales transcurrían por dinámicas absolutamente sectarias, sin dar oportunidades a los candidatos adictos que no gozaban del favor de los jerarcas municipales y gubernativos, con lo cual en 1948 habíanse sentido frustrados los miembros de la opción tradicionalista que concurrieron a las urnas y en 1951 los católico-integristas atraídos para dar color a los comicios ${ }^{21}$, a pesar de ser éstos considerados por un anónimo informante de Acedo Colunga como aceptables y mucho mejor candidatos que los oficiales ${ }^{22}$. La primera tarea del nuevo gobernador ci-

20 Carmen de Lirio y Baeza Alegría eran ciertamente viejos conocidos y paisanos, pero el gobernador no legó a figurar nunca, a lo que parece, en la lista de sus amantes, a diferencia de algunos de los jóvenes leones falangistas de la Barcelona de aquellos años, como por ejemplo Juan Antonio Samaranch. Ver Jaume BOIX \& Arcadio ESPADA, E/ deporte del poder. Vida y milagro de Juan Antonio Samaranth, editorial Temas de Hoy, Madrid 1991, págs. 39-58, donde se relatan entre otras cosas la andanzas de la Brigada del amanecer, como llegó a conocerse a la cuadrilla en la que se divertia el futuro dirigente olímpico.

21 Sobre las fórmulas para organizar elecciones de un modo convincente, sin correr el riesgo de perderlas, véanse los documentos: Normas generales sobre las elecciones del Tercio de Concejales que queden vacantes por los residentes majores de edad y de vecinos caberas de familia. (1948), Fondo del Gobierno Civil de Barcelona (FGCB), caja núm. 845, Archivo de la Corona de Aragón (ACA); indice de Directrices Politicas para la celebración de las elecciones de Concejales. (1951), id.; Reservado. (1954), instrucciones para Delegados Sindicales Provinciales, FGCB, caja núm. 854, ACA.

22 Observaciones ante las elecciones municipales, documento sin fecha ni firma, escrito seguramente hacia septiembre-octubre de 1951, FGCB, carpeta núm. 884, ACA.

Hipania, LVIII/2, nưrn. 199 (1998) 655-6 
vil, con equipo renovado y junto con el también nuevo alcalde Antonio María Simarro, amigo personal del Ministro de la Gobernación Blas Pérez González de sus años de estancia como profesor en la Universidad de Barcelona y de su actividad profesional en la ciudad, sería, pues, la completa renovación tanto del equipo de gobierno municipal como de lo que Miguel Jerez Mir bautizó como los centros de extracción de las élites políticas locales en toda la provincia ${ }^{23}$.

Acedo consiguió éxitos notables en esta tarea a través de numerosas destituciones y hábiles nombramientos que vincularon a la administración local a ex-regionalistas, católicos de militancia diocesana y otros sectores localmente influyentes, fieles franquistas pero ajenos al mundo cerrado de FET-JONS, donde pululaban ex-combatientes y ex-cautivos de muy diverso origen político de preguerra o carentes de él, en una situación de aislamiento social creciente. En Arenys de Mar el grupo monárquico-calvosotelista que había configurado la FET-JONS local y ocupado el consistorio desde 1939 tuvo que ceder el paso en 1952 a un conglomerado de ex-regionalistas y falangistas de nuevo cuño bajo la dirección del alcalde de la Lliga Regionalista de los años treinta. En Badalona ex-regionalistas i católico-integristas, antiguos compañeros dentro de la Federació de Joves Cristians de los años treinta, vinieron a sustituir en 1954 a los monárquico-tradicionalistas que con consideración de vieja guardia campaban por sus respetos en el municipio. El eterno alcalde de Sabadell Josep Maria Marcet (1940-1960) tuvo que renovar con jóvenes católicos y ex-militantes del Frente de Juventudes un consistorio de ex-combatientes de distintos orígenes a partir de las elecciones de $1954^{24}$. Los numerosos ejemplos que pueden citarse y sus múltiples peculiaridades, en la misma sintonía de cambio de personal dentro de los cítculos de probada fidelidad al régimen, nos llevarían a otro artículo.

Cabe decir, con todo, que este conjunto de renovaciones no parece seguir en nada la pretendida secuencia lógica del franquismo de pasar del nacionalsindicalismo al nacionalcatolicismo como dos fases claramente individualizadas, momento en cual se bubiera debido de dar paso a los monárquicos y/o a los católicos en detrimento de falangistas y demás fascistizados según las interpretaciones al uso. La lógica seguida fue más bien la de romper el monopolio de la generación de la Guerra Civil, donde se podía encontrar a una amplia variedad de alfonsinos e integristas de preguerra, por ejemplo, licenciándola progresivamente en favor de jovenes falangistas formados dentro del partido, militantes de la Acción Católica Diocesana, sustancialmente distintos de los de la elitista Asociación Nacional Católica de Propagandistas (ACNP) que estaban instalados en sillones ministeriales y cátedras universitarias, y también ex-regionalistas rescatados del baúl de los recuerdos. Conviene no dejarse llevar por la tenta-

\footnotetext{
23 Miguel JERÉZ MIR, Élites politicas y centros de extracioón en España, 1938-1957, CIS, Madrid 1982.

24 Sobre el caso particular de Sabadell pueden consultarse mis trabajos Franquisme $i$ poder local l'Ajuntament de Sabadell, 1939-1979., memoria de doctorado inédita, UAB 1990 i L'Ajuntament de Sabadell en el periode franquista: l'articulació politica municipal, 1939-1979. en Arraona. Revista d'Història, núm. 9, Sabadell 1991, págs. 81-94.
}

Hispania, LVIII/2, núm. 199 (1998) 555-678 
ción de pensar que las dinámicas de equilibrio político jugadas en torno al Consejo de Ministros pueden fácilmente aplicarse al juego político provincial como si se tratase de la extensión de un juego de partidos encubierto. En la política provincial, aparte de los condicionantes locales, jugó casi exclusivamente la voluntad del Ministro de la Gobernación Blas Pérez González (1942-1957) que exa quien controlaba los resortes fundamentales, con lo cual existía un cortocircuito lo suficientemente notable como para no poder caracterizar la dinámica política general como de gobiernos de coalición 25 y familias políticas. A la hora de caracterizar el juego político del franquismo, este divorcio aparente entre política madrileña y política periférica cabe explicarlo a partir de una interpretación en clave clientelar mucho más que familiar, dado que la conexión que se establecía entre las jerarquias del régimen o sus notables y las dinámicas políticas de pravincias tenía su lógica puesta en relaciones personales, en juegos de pattonazgo y deferencia como los que se han descrito para otros contextos políticos basados en la pugna de grupos de notables ${ }^{26}$.

Acedo consiguió en Barcelona-ciudad tan sólo éxitos parciales. En 1951, con escaso conocimiento del terreno, fracasó en toda regla, reconociéndolo amargamente en sus informes a la supetioridad ${ }^{27}$. Pero además chocó con un alcalde que se instaló tan cómodamente como su antecesor en la Plaza de Sant Jaume sin afrontar los retos que se plantearon con el fin de los sucesos de 1951. Acedo tenía que exponérselo al ministro con todo tacto, para no cargar en exceso las tintas contra su amigo el alcalde, en un apartado del informe de 1954 que no me resisto a reproducir:

"Reconociendo en general al Alcalde bonestidad económica, inteligencia clara y lealtad politica, se le niega eficacia y decisión. Yo por mi parte creo que esto es verdad aunque gran parte de ella tiene su explicación en su sentido comodón de la vida que le lleva a querer tener unos colaboradores mansos y entregados con to que resulta un equipo de ineptos, de bolgazanes o en definitiva de «buenos cbicos» que no tienen ninguna personalidad.» 28

Con la mirada puesta tan sólo en el orden público y la eficacia relativa de lo ya ensayado Blas Pérez continuó confiando en su amigo Simarto para desesperación de Acedo. De esta forma el mayor presupuesto público de Cataluña, en

25 Así ha definido los gobiernos de toda la dictadura franquista Javier TUSELL en Franco en la Guerra Civil, p.229. Para una crítica de ese uso del término coalición vid. R. L. CHUECA i J. R. MONTERO, El fascismo en España: elementos para tma interpretación, en Historia Contemporánea, núm. 8, 1992, pág. 218 .

26 En este sentido propuse reexaminar las interpretaciones/descripciones del juego politico franquista en mi comunicación La politica dins el règim franquista famílies o clienteles? Algunes aportacions des de la prespectiva microhistòrica, en I Encuentro de Investigadores de/ Franquismo, Fundació Arxiu Històric de Comissions Obreres de Catalunya (CONC) / UAB / Societat Catalana d'Estudis Històrics, Barcelona 1992, págs. 43-46.

27 Borrador del informe de Acedo a Bla ; Pérez durante el período electoral de 1954, 22 de noviembre de 1954, FGCB, carpeta núm. 898, ACA.

28 Informe de Acedo a Blas Pérez, id. 
crecimiento moderado pero constante a causa de la recuperación económica relativa de los años cincuenta, siguió controlado por un equipo sin ningún tipo de proyecto de ciudad, sin respuesta para las demandas ciudadanas ${ }^{29}$, sin interés por ensanchar su base social y crecientemente afectado por escándalos de tipo económico que a duras penas se podían ocultar a la luz pública ${ }^{30}$. De nada sirvió que en 1954 Acedo suspendiera las elecciones familiares de la Ciudad Condal para mejor distribuir los puestos de concejal entre un florido ramillete de jóvenes franquistas, de diversa condición, junto a supervivientes del lobby regionalista, muchos de ellos con un brillante futuro por delante dentro del régimen y en algún caso incluso después de él. Aquel año Simarro se vería obligado a acoger en su lánguido equipo municipal, entre otros, al presidente de la Acción Católica barcelonesa, Santiago Udina Martorell, futuro vocal de la Comisaría del Plan de Desarrollo (1962) y Subsectetario de Obras Públicas (1965-70); al albacea testamentario del mismísimo Cambó, Narcís de Carreras, más tarde Procurador Familiar en Cortes (1967-71) y presidente del F.C.Barcelona (1968-69); al empresario y yerno del ex-ministro regionalista Ventosa Calvell, Santiago de Cruilles, promocionado, más adelante, a Director General de Transportes Terrestres (1965-69) y Subsecretario de Gobernación (1969-73) y a un joven falangista protegido del permanente Consejero Nacional de FETJONS Mariano Calviño de Sabucedo - uno de los Cuarenta de Ayete-, un tal Juan Antonio Samaranch... Prácticamente ninguno de ellos accederia a cargos de auténtica responsabilidad dentro del consistorio hasta el cese de Simarro en 1957.

Acedo obtuvo con el cese de Simarro, tras el nombramiento de Camilo Alonso Vega como nuevo ministro de la Gobernación, una victoria pírrica en su propósito de mantenerse como el intermediario entre el gobierno y su ámbito provincial con los ex-regionalistas como aliados y un ensachamiento de la base política franquista en general. Con la marcha de Blas Pérez el ministerio cedía en poder político tanto por la personalidad de su nuevo titular, poco dado a las sutilezas del mismo, como por la basculación que éste seguía hacia los despachos de la Presidencia del Gobierno ${ }^{31}$. El general Camilo Alonso Vega no iba a seguir avalando políticas complejas de atracción hacia quienes a pesar de encontrárse aún sólidamente instalados en el tejido industrial, financiero y profesional de Cataluña, resultaban figuras en retroceso en la recta final hacia la liberalización económica parcial que daría paso al desarrollismo. Alonso Vega no se había planteado este género de cuestiones, tal y como demuestra que eligiera para sustituir a Acedo en 1960 a un personaje adicto y útil en Canarias, pero no

29 Véanse, por ejemplo, las quejas recogidas por los servicios de información de FETJONS: Nota informativa. Asunto: Transportes urbanos, $11-V-1953 ;$ Nota informativa. Asunto: Ayuntamiento, 1-VI-1953, FGCB, carpeta núm. 878, ACA.

30 Documentación diversa con cruces de acusaciones entre concejales, alcalde y funcionarios, FGCB, carpeta núm. $879, \mathrm{ACA}$.

31 Así lo ha explicado de forma convincente Javier TUSELL, Carrera. La eminencia gris del régimen de Franco, Temas de Hoy, Madrid 1993, especialmente págs. 177-264.

Hispar:a, LVIII/2, núm. 199 (1998) 655-678 
demasiado hábil en Barcelona, como Matías Vega Guerra ${ }^{32}$. Así pués, Acedo no consiguió situar a su candidato Félix Escalas como nuevo alcalde. El protegido del gobernador era, consecuentemente con la política seguida por el mismo durante más de un lustro, un representante de aquellos políticos regionalistas que seguian jugando un papel básico en la economía del Principado a través de su control del sector textil, pero que desde 1939 se habían visto desplazados de la cuota catalana de cargos públicos y la capacidad de influen ria en la designación de los mismos por el conglomerado de sus rivales españolistas de pre y postguerra: falangistas (Mariano Calviño, Carlos Trías Bertran, José Maria Fontana), alfonsinos de DC/RE i/o de la anterior Dictadura (Demetrio Carceller, Eduardo Aunós, Alfonso Sala -padre e hijo-), monárquicos exautonomistas (Miquel Mateu), tradicionalistas reconvertidos (Joaquín Bau), etc. Ahora, con Gual Villalbí como ministro catalán sin cartera —un hombre del Fomento del Trabajo Nacional, la veterana patronal catalana aún bajo control de los textiles algodoneros- alguien con un currículum como el de Escalas, antiguo Gobernador General de Cataluña en el periodo de suspensión del Estatuto y en aquel momento Presidente de la Camara de Comercio de Barcelona-parecía tenerlo todo a su favor. Pero el nuevo inspirador de la política del franquismo hacia Cataluña, situado a la sombra de Carrero Blanco, el catedrático natural de Barcelona Laureano López Rodó, se había propuesto romper con la dinámica de tener un ministro catalán como interlocutor económico y a los gobernadores como controladores políticos. El proyecto de López Rodó, intersectado con el de infiltración del Estado por parte de los miembros del Opus Dei, pasaba por tener a un hombre fiel en el puesto de mayor responsabilidad en Cataluña y éste no era otro que la alcaldía de Barcelona. El gobernador de Barcelona debia ocupar un segundo plano, como ya sucedía con el presidente de la Diputación, ligado básicamente a la conservación del orden público, dado que no era sencillo desplazar de ese puesto a los militares ${ }^{33}$. De estos círculos surgió el nombramiento del nuevo alcalde, dejando al gobernador Acedo en fuera de juego. Se trató del que fuera en su día, Presidente de la Diputación de Lleida (1940-43) y Director General de Registros y Notarías (1943-45) siendo Ministro Eduardo Aunós, el entonces notario instalado en Barcelona desde

32 Matías Vega Guerra, abogado canario que venía de haber presidido el Cabildo Insular de Gran Canatia durante quince años (1945-60), fue el primer gobernador civil de Barcelona des de 1940 con un perfil curricular no militar. Su indolencia en todo lo que no fuera orden público quedó de manifiesto en las inundaciones del Vallés de 1962, tras las cuales fue cesado y destinado como embajador a Venezuela (1963-70), donde tantos canarios, como el propio Blas Pérez, tenían negocios. Sobre su actuación al frente del Cabildo ver José AI.CARíz ABELLAN, Matias Vega Guerra, Ed.Benchomo, Las Palmas de Gran Canaria/Santa Cruz de Tenerife 1994.

33 A Matías Vega Guerra les sustituiria el militar Antonio Ibáñez Freire (1963-66) que amenazó con «comperle los dientes de un culatazo» a Jordi Pujol en aquel entonces - Manuel OR'IlINEZ: Una vida entre burgesos. Memòries, Ed. 62, Barcelona 1993, pág. 128--, y, curiosamente acabó siendo Mínistro del Interior en demozracia (1979-80). Después vendría aún el jurídico militar Tomás Garicano Goñi (1966-69), también Ministro de la Gobernación (1969-73). 
1947, José María de Porcioles. Curiosamente un antiguo cuadro del tardío regionalismo ilerdense, aunque hubiera nacido en Amer, Girona.

Era preciso acometer los nuevos tiempos con interlocutores más cercanos a las nuevas dinámicas sociales de lo que podían serlo unos cuantos burócratas del Movimiento, ex-combatientes nostálgicos o veteranos del carlismo de una u otra rama, sin alterar por ello ninguna de las directrices fundamentales de funcionamiento político: unidad (ante la opinión pública), disciplina (para acatar las órdenes de la superioridad fueran en la dirección que fueran) y jetarquía (para no cuestionar/debilitar la pirámide del mando). A partir de ese momento la relación iba a ser directa entre el alcalde de Barcelona y las altas esferas del régimen: algo que no sucedía desde el cese de Miquel Mateu Pla en 1945 por gozar éste de la confianza personal de Franco y del cargo de Consejero Nacional de FETJONS, además de ser sobrino del cardenal Pla y Deniel. Esa y no otra condición pondría Porcioles a la aceptación de su nombramiento: su acceso directo al Pardo y a los círculos ministeriales sin intermediarios gubernativos.

\section{PORCIOLES Y EL PORCIOLISMO}

El nuevo alcalde daría la medida de sus posibilidades en la renovación de la política local del régimen sin salirse de sus justos límites. Su juego fue tan simple, o tan complicado, como el lema que presidió su legada al consistorio: las tres «C», Carta Municipal, Castillo de Montjuic y Compilación del Derecho Civil Catalán. Tan simple porque, de hecho, Porcioles no dió salida alguna a los graves problemas que atenazaban a la ciudad. Al contratio, planteó nuevos y graves problemas al abonar una política de fiebre constructora sin ningún tipo de control real de la actividad privada - ni prácticamente de la pública-, pasando por encima de la única planificación urbanística de carácter globalizador que se encontraba vigente, la derivada del estudio de la Comisión Provincial de Urbanismo de 1953, pasándose del problema de la inactividad al de la actividad caótico-especulativa. Tan simple porque la Carta significó un nuevo modus vivendi que no modificó de manera importante la lógica municipal del régimen definida en la postguerra ${ }^{34}$. Tan simple porque tanto el tema de la cesión de la antigua fortaleza militat de Montjuic a la ciudad como el de la Compilación fueron operaciones propagandísticas más que realizaciones con contenido para el común de los ciudadanos. Pero, contradictoriamente, tan complicada que le permitió hacerse valorar por el régimen lo suficiente como para mantenerse en el cargo por espacio de quince años, pese a las críticas y a la hostilidad de los sectores más cerriles del aparato gubernamental ${ }^{35}$. De paso aprovecharía su

34 Un buen resumen se encuentra en Francisco MARTÍ y Eduardo MORENO, Barcelona za dónde var?, Dirosa, Barcelona 1974, así como en el diccionario VV.AA.: La Barcelona de Porcioles, Laia, Barcelona 1975.

35 Criticas y hostilidad que han resaltado los panegiristas de Porcioles hasta nuestros dias. Ver Manuel VIGL y VAZQUEZ, Entre el franquismo y el catalanismo. Con Picasso en medio, Plaza \& 
ventajosa posición para pasar de ser un ciudadano de considerable nivel de vida a una de las diez mayores fortunas del país en el momento de su cese ${ }^{36}$, proyectando a toda una red de empresarios, abogados, atquitectos y demás personal de una nueva burgesía managerial caracterizada por su pertenencia a múltiples consejos de administración más que por su control personal sobre las empresas, vinculada al crecimiento urbano de la Gran Barcelona.

Ciertamente que no se debieron a Porcioles ni a ningún otro jerarca del régimen los éxitos de la producción industrial de los años cincuenta-sesenta. Cuestiones relativas a las ventajas comparativas de la localización empresarial, de la disponibilidad de mano de obra especializada - la otra llegaría por remesas incontenibles- y, en definitiva, procesos de economías de escala empujaron a la industria catalana durante el periodo desarrollista una vez superadas algunas de las principales rigideces del modelo autárquico de la larga postguerra. Este proceso de crecimiento se encontraba ya iniciado cuando en 1957 se produjo el relevo en el ayuntamiento de la Ciudad Condal. La extensión de la ciu$\mathrm{dad}$ en mancha de aceite, con nuevas construcciones industriales y residenciales, al calor de la prosperidad económica era un tema tanto barcelonés como de otras areas urbanas españolas y europeas en general, aunque en Barcelona la ya tradicional localización industrial convertía en foco de crecimiento a la mayor parte de la provincia. El fenómeno del crecimiento urbano en los polos de industrialización de la Europa del Sur ${ }^{37}$, retrasados en sus procesos de urbanización respecto de la Europa Atlántica revestía no obstante una particularidad doble. El éxodo rural interior implicaba en los años mencionados a un número mucho mayor de ciudades y ciudadanos que en cualquier otro lugar y época anteriores en un conjunto de países con regimenes políticos ciertamente diversos: el triángulo Milán-Turín-Génova en Italia, Belgtado y Split en Yugoslavia, Atenas y Tesalónica en Grecia, incluso Bucarest en Rumanía o Estambul en Turquía. Las grandes aglomeraciones metropolitanas generaban necesidades de vivienda y urbanización sin precedentes, con su corolario de habitat sub-integrado de bidonvilles, autoconstrucción precaria y centros urbanos deteriorados. Junto a ellas aparecía por primera vez la posibilidad de atender esa demanda de una forma rápida y relativamente asequible a través de la industrialización del proceso de fabricación del material de construcción y de los propios procesos

\footnotetext{
Janés, Barcelona 1981, donde se resalta el supuesto liberalismo del nuevo alcalde y su catalanismo bién entendido. Significativo también el libro de José TARIN-IGLESIAS, Vivir para contar, Planeta, Barcelona 1982, que opone a Porcioles como catalanista frente a un anticatalanista Acedo.

36 Los más ricos de España, en el semanatio Las Españoles, núm.4, 16-IV-1973.

37 Ver A. BOLTHO (ed.), The European Economy. Growth \& Crisis, Oxford University Press, Oxford 1982, G. FUA, Problemes du développement tardif en Europe, OECD, 1980 y Giulio SAPELLI, Dalla periferia allintegrazione europea, Einaudi, Turin 1991.

38 Ver Xavier TAFUNELL, La construcció: una gran indústria $i$ un gran negoci, en VV.AA., Història Econòmica de la Catalunya Contemporánea, vol. 6, Ed.Gran Enciclopèdia Catalana, Barcelona 1989, págs. 211-241.
} 
constructivos ${ }^{38}$. Surgían las urbanizaciones verticales. Ésta y no otra sería el área concreta en la que el entramado porciolista aparecería en escena como motor de actividad económica. La planificación urbanística y no su ausencia fue precisamente el engranaje que permitió poner en funcionamiento la complejidad de relaciones político-económicas tejidas por el ayuntamiento barcelonés sin salirse de los márgenes de una legalidad política concebida como fascista que no evolucionó en demasía, como veremos, con el régimen de la Carta.

Resulta difícil establecer, con todo, un paralelismo entre las gestiones llevadas a cabo por las administraciones italiana fascista y franquista, contrariamente a como se han establecido las similitudes entre sus marcos organizativos. No puede ser de otro modo dadas las diferencias de calendario. En los años veinte y hasta que no se produjo la crisis económica internacional el éxodo rural italiano se canalizaba hacia el exterior. Los países receptores fueron básicamente los Estados Unidos y Argentina. Ya en los años treinta - cerrada la puerta americana - intentó reorientarse la migración hacia las colonias africanas de Libia y, desde 1935, Etiopía. Las ciudades italianas no crecieron significativamente y ello permitió concentrar las energías en macroproyectos urbanísticos como el que transformó el centro histórico de la ciudad de Roma infringiendo irreparables daños a la investigación arqueológica i a su patrimonio histótico menos aparente ${ }^{39}$. El paralelismo más acentuado debe centrarse en la falta de actividad de los municipios italianos de los años treinta, reeditada con abundamiento por los españoles de los años cuarenta y cincuenta, como ya hemos visto.

Al tomar posesión de la alcaldía de Barcelona Porcioles tenía ante sus ojos una realidad de hábitat precario y de déficit de vivienda, equipamientos y servicios ciertamente pavorosa. Existía un conjunto de barrios periféricos de caótica distribución y una disponibilidad relativamente amplia de terrenos dentro del término municipal. Al finales de su mandato ya en los años setenta se calculaban en un $40 \%$ los habitantes de Barcelona que seguían viviendo en areas de babitat subintegrado to. Los déficits de equipamientos y servicios habian aumentado, en especial el de plazas escolares, y toda la planificación anterior había sido desnaturalizada al coste de agotar el término municipal casi por completo sin reservar apenas espacio para las zonas de uso público y en especial para las zonas verdes ${ }^{41}$. Pero este crecimiento depredador de los espacios de uso público permitió que diversos lobbys económicos tejietan en torno a la ciudad una compleja red de relaciones que hacía de la fidelidad política al régimen, a través del alcalde, un arma decisiva para su sustento. El propio alcalde perteneció como personaje central a uno de ellos, del que formaban parte, sin

39 Vid. A. CEDERNA, Mussolini urbanista. Lo syentramento di Roma negli anni del consenso, Laterza, Bari 1981.

40 Ver VV.AA., La Gran Barcelona, Alberto Corazón, Madrid 1972, págs. 62-67 a cargo de Jordi BORJA.

41 Una valoración de conjunto en la introducción del diccionario La Barcelona de Porcioles, cit., págs. 5-16.

Hispania, LVHIL/2, núm. 199 (1998) 655-678 
pretensión de exhaustividad, el Banco Condal, el Banco de Madrid, la financiera Fidecaya, la constructora Spai, los rotativos Nuevo Diario y ElNoticiero Universal, el Grupo Inmobiliario Figueras-Bassols, el Consorcio Túneles del Tibidabo, Hubbet, Traesa, Gocisa, Enher, Demsa, etc. En su interior trabajaban los primeros tenientes de alcalde de Porcioles, Félix Gallardo Carrera y Juan Bta. Beltrán Flórez, el por más de una década Delegado de los Servicios de Urbanismo y Obras Públicas, Guillermo Bueno Hencke, los empresarios Joan Gaspart, José Maria Figueras y Ildefons Suñol, el Presidente de la Diputación de Barcelona José Maria Muller y de Abadal, y los yernos del propio alcalde, Manuel Vall y Alfredo Briales. Todos los mencionados se sentaban junto con Porcioles en algún consejo de administración —o en más de uno-o bién actuaban en la vida económica de la ciudad a través de su notaría. El modelo Porcioles fue adaptado a escala por otros alcaldes del momento a la hora del despegue urbanístico de sus ciudades (notoriamente Rincon de Arellano en Valencia, 1958-69), pero sin duda fue el alcalde de Barcelona el caso más temprano y de proporciones mayores. Está fórmula para mezclar escandalosamente política y negocios privados tuvo derivaciones en otros niveles: por ejemplo Samaranch figuró entre los promotores de la construcción del lastimoso barrio de Ciudad Meridiana en los límites del término municipal, no hubo empresa ni grupo que dejara de meter sus manos en la urbanización alegal - por no decir ilegal- de la desembocaduta del Besòs, concejales diversos jugaton en pequeña escala para obtenet para sí o para sus allegados pequeñas y grandes ventajas dentro de una Barcelona que estaba permanentemente patas artiba. És decir, que junto al gran lobby municipal crecieron otras grandes redes de tráfico de influencias, y, a su sombra, se desarrollaron también inicativas más modestas.

Así de apoliticamente se construyó el consenso básico al franquismo en los años sesenta en Barcelona. Porque en él cupieron todos, ya fueta como cargos públicos, como hombres de negocios o como ámbas cosas: hombres del Movimiento como Calviño (Consejo Nacional de FET-JONS y Procurador en Cortes), Ribas Seva (teniente de alcalde, 1960-63), Samaranch (Presidente de la Diputación, 1973-77) y Gallardo Carrera (teniente de alcalde, 1970-79), opusdeístas como Bueno Hencke o el propio Porcioles, empresatios sin color político como los miembros del clan Figueres-Bassols y otros muchos del tipo que hemos designado como managerial y que tuvo su gurú en un personaje como Pere Durán Farell (Hidroeléctrica de Cataluña, Catalana de Gas y Electricidad, La Maquinista Terrestre y Marítima, Banco Urquijo), que llegaría a sonar como alcaldable en el relevo de Porcioles.

Lo significativo ante tal modo de ejercerse el juego político (amigos, clientelas, patrones, protegidos, adictos, fieles, rivales, competidores) fue que no variaran las estructuras fundamentales que le sirvieron de marco, y que cuando éstas lo hicieron fue para dar una nueva vuelta de tuerca al esquema centralizador. Si la corporación municipal estaba en manos del alcalde y éste en manos del Ministerio de la Gobernación hasta la aprobación de la Carta Municipal, ello siguió siendo así después, con pequeñas variaciones. Gobernación cedió ante la influencia creciente de Presidencia del gobierno, y Porcioles puso bajo 
su control personal, más aún si cabe, al consistorio a través de la reducción del número de miembros de la comisión permanente del mismo - con celebración cotidiana de plenillos en los que se decidía anticipadamente qué se iba a aprobar en el pleno del día siguiente- $y$, fundamentalmente, con la creación de los Delegados de Servicios. Esta figura, de libre designación del alcalde y responsable tan sólo ante el mismo, hurtó responsabilidades a tenientes de alcalde y concejales y contribuyó a generar una gestión mucho más opaca a los ojos de la opinión pública. Porcioles, por lo tanto, actecentó el poder personal del alcalde franquista ante sus subordinados jerárquicos mientras daba la imagen a los medios de comunicación de que estaba aumentando el nivel de autonomía del ayuntamiento. Nada incompatible con el esquema fascista heredado, tan cercano al desartollado en Italia en el periodo de entreguertas. Y es que no existía contradicción entre el control político centralizado y el ofrecimiento al público de un rostro amable que contrastata con el negro periodo de los años cuarenta-cincuenta. Eran dos caras de la misma moneda, el Porcioles feroz acrecentador del poder político de la alcaldía a mayor gloria del régimen era también el Porcioles que innauguraba el Museo Picasso o bailaba sardanas en público. De la misma forma que fueron la misma persona los tres periodos que de Alessandro Pavolini conoce la historia italiana. En primer lugar el culto y tefinado Secretario Provincial del Partito Nazionale Fascista de Florencia en los años treinta, jugando a engrandecer la imagen de la ciudad como capitale dellin telligenqa italiana, a través de ferias y congresos, con una nueva y moderna estación de ferrocarriles y con su protección personal a ciertos poetas e intelectuales liberales en el periódico del partido, "Il Bargellos ${ }^{42}$. En segundo lugar el filo-nazi ministro de Cultura Popular (1939-43). Y en tercero el sangriento Secretario General del Partito Fascista Reppublicano, con rango de ministro, de los años de la Reppublica Sociale Italiana (1943-45). Pavolini jamás dejó de ser fascista, en su caso con uniforme incluido; demostró únicamente que sabía afrontar de modo diferente periodos de consenso y periodos de guerra civil abierta. Al fin y al cabo el Porcioles identificado con el Opus Dei i el sector tecnócrata del gobierno en los sesenta, era un ex-combatiente de la Cruqada con cargo provincial en Lleida dentro de FET-JONS a principios de los cuarenta. Cargo al que le había conducido su amistad con Mercedes Sanz Bachiller, la falangista viuda de Onésimo Redondo ${ }^{43}$.

Por su parte la administración periférica del estado siguió usurpando competencias a la administración local y provincial después de 1960, con lo cual resulta difícil ver algún otro rastro de mayor margen de autonomía que el incremento de las dotaciones presupuestarias. Incremento que bastaria para justificar una imagen de autonomía relativa si no hubiera llevado aparejado un incremento galopante del déficit municipal, que a la altura de los años setenta había vuelto a colocar a Barcelona y a la mayoría de los ayuntamientos urbanos

42 Vid. Matco PALLA, Firenze nel regime fascista (1929-1934), Olschki, Florencia 1978.

43 Asi lo cuenta el interesado en sus escritos publicados póstumamente, José Matía de PORCIOLES, Mis memorias, Ed. Prensa Ibérica, Barcelona 1994, págs. 47-52.

Hipania, LVIII/2, núm. 199 (1998) 655-678 
de la zona al borde de la quiebra. En cuanto al rasgo de autonomía que el poder creciente de Porcioles pudiera significar hay que ponerlo en cuarentena. Su poder se incrementó en gran medida mientras gozó de la confianza de arriba: conquista de la Diputación, de donde consiguió sacar a su rival ocasional en el control de la expansión de Barcelona a través de los túneles del Tibidabo, Joaquín Buxó-Dulce d'Abaigar, marqués de Castellflorite, y control sobre el area metropolitana con el cese de alcaldes conflictivos como el de Hospitalet José Matías de España Muntadas. Pero éste se apagó como por ensalmo cuando el nuevo Ministro del Interior Tomás Garicano Goñi le relevó en 1973. Su cese sirvió para dar la alternativa, a través del nuevo alcalde Enrique Masó, a otro lobby industrial y financiero, rival del porciolista, y al que era próximo el propio ministro. Garicano, ex-gobernador civil de Barcelona (1966-69) se libraba así de un hombre de Carrero y López Rodó situando a uno propio, en lugar de aceptar la tutela de Presidencia para los nombramientos tal y como había hecho a menudo su antecesor en el cargo Camilo Alonso Vega.

Tan fácilmente como había subido volvió a bajar. El poderoso Porcioles era un colaborador del alto mando franquista, no un auténtico poder local con su propia zona de dominio. El poder le fue otorgado y en torno a él creo su base política. Cuando le fue retirado, su base política se desintegró rápidamente: cuando tres años después se inició la Transición no hubo ningrin grupo que se presentara como su continuación.

En 1973 el ayuntamiento de Barcelona entró en una nueva fase. Sangre joven procedente del mundo empresarial forjado en los años del porciolismo vino a reemplazar a Porcioles: Enrique Masó Vázquez, un hombre de negocios con muy buenas relaciones -incluso en los EE.UU.- llegó a la Plaza de Sant Jaume dispuesto a reeditar con nuevos rostros la aventura de los años precedentes y a resolver los angustiosos problemas de tesorería del municipio. No consiguió ninguno de sus objetivos. Los tiempos estaban cambiando y mientras el aparato del estado era incapaz de responder con eficacia al colapso económico de la administración local, la oposición antifranquista conseguia teñir de matices políticos todas y cada una de las demandas sindicales y vecinales. $\mathrm{Si}$ el juego empresarial era reconvertible hasta su ampliación, con tal de contar con el emergente papel de Samaranch al frente de la Diputación, no era tan simple compaginar éste con la atención de las ingentes necesidades ciudadanas o con el respeto a sus derechos más elementales en forma de servicios. Masó dimititía en 1975. Desde entonces en adelante la historia de la descomposición del régimen local franquista iba a tomar un ritmo vertiginoso.

\section{ALGUNAS CONCLUSIONES}

Aunque no pueda extrapolarse el funcionamiento de la administración lo$\mathrm{cal}$, ni siquiera la del aparato gubernativo provincial, al del conjunto del régimen franquista, no cabe duda de que fue una de sus partes constitutivas de 
mayor importancia para mantener el consenso - sea este activo o pasivo- y el control -más o menos coetcitivo- del conjunto de la población.

Tanto el régimen local como el complejo gubernativo del franquismo fueron concebidos como fascistas. Esto es, aparatos paralelos a los que se diseñaron en otros de los paises en los que en el periodo de entreguerras se impusieron dictaduras de partido único, antiliberales, antidemocráticas, y anticomunistas, dispuestas a elevar los mecanismos del estado de excepción a la categoría de norma y con voluntad de ejercer un control sindicalizado sobre la población trabajadora tanto rural como urbana. El conjunto de instituciones afectadas, ayuntamientos, diputaciones y gobiernos civiles, no variaron sustancialmente su fórmula de funcionamiento desde que fue establecida, entre el segundo año de la Guerra Civil y mediados de los años cuarenta, hasta la transición política de la segunda mitad de los setenta. Los experimentos modernizadores en política municipal se realizaron dentro de este marco, tespetando sus mecanismos básicos y acentuando su tendencia al control centralizado de la toma de decisiones. Así sucedió con el más complejo de todos ellos en la Barcelona del desarrollismo. Vistas así las cosas, ¿no resulta algo más complejo desterrar la palabra fascismo del vocabulario usado para definir al franquismo avanzado e incluso tardio, por más que FET-JONS - no lo olvidemos, una parte y no el todo de un régimen fascista- jugara cada vez un papel menos aparente? 